\title{
The Implementation of a Mobile APP for Cancer Care Management at the Brazilian National Cancer Institute
}

\author{
Emmanuel Tenorio Cavalcante PIRES ${ }^{\mathrm{a}}$, Cezar $\mathrm{CHENG}^{\mathrm{a}}$, \\ Sandro Luís Freire de CASTRO SILVA ${ }^{\mathrm{a}, 1}$, Sandra Regina GOIS ${ }^{\mathrm{b}}$, \\ Francisco Santos SABBADINI ${ }^{\mathrm{c}}$ and Antônio Augusto GONÇALVES ${ }^{\mathrm{a}, \mathrm{b}}$ \\ a Instituto Nacional de Câncer - COAE Tecnologia da Informação, \\ Rua do Resende 195, Rio de Janeiro, 20230-092, Brazil \\ ${ }^{\mathrm{b}}$ Universidade Estácio de Sá - MADE, \\ Avenida Presidente Vargas 642, Rio de Janeiro, 200071-001, Brazil \\ ${ }^{\mathrm{c}}$ Universidade do Estado do Rio de Janeiro - UERJ \\ Rod Pres Dutra km 298, Resende, 27537-000, Brazil
}

\begin{abstract}
There is increasing recognition of the potential to use mobile health (mHealth) technologies such as smartphone apps to support clinical care. Mobile apps are progressively being implemented to manage chronic diseases like cancer to improve patient care. The app deployed at the Brazilian National Cancer Institute enables patients to access the appointments/exam booking, medication prescription, and cancer-prevent educational resources, improving self-management, autonomy, and cancer treatment outcomes in resource-limited environments. Despite acknowledging the importance of mHealth, research is still scarce regarding patients' views on using these innovations in cancer care management.
\end{abstract}

Keywords. Mobile App, mHealth, Cancer Care.

\section{Introduction}

Population aging, improvements in information and communication technologies (ICT), and advances in public health care have introduced additional telecare services requirements. In this regard, ICT innovations revolutionize chronic patient care, providing real-time monitoring for health professionals [1].

There is increasing recognition of the potential of mobile health (mHealth) technologies such as smartphone apps in optimizing clinical care. Mobile phones currently represent a technology present in patients' daily lives. They enable access to different information and healthcare services independent of the time and place. This connectivity offers excellent opportunities to use mobile technology for improving healthcare services $[2,3]$.

Mobile apps are progressively being implemented to manage chronic diseases, improving patient care. Although the potential benefits of mHealth seem particularly

\footnotetext{
${ }^{1}$ Corresponding Author, Sandro Luís Freire de Castro Silva, Instituto Nacional de Câncer - Tecnologia da Informação, Rua do Resende 195, Rio de Janeiro, 20230-092, Brazil; Email: sandrofreire@gmail.com.
} 
suitable for monitoring chronic diseases like cancer, the treatment success depends on patient compliance. Cancer treatment is accomplished through intensive and prolonged ambulatory procedures that frequently occur outside the hospital units, representing a significant challenge [4]. Mobile health (mHealth) is a broadly accessible technology that provides health services through portable devices [5]. The implementation of mHealth initiatives has been positive, particularly in cancer care management and follow-up [6,7]. Despite acknowledging the importance of mobile health apps, research still scarce regarding patients' views on using these innovations in cancer care management.

\section{Method}

The project was conducted at the Brazilian National Cancer Institute between January 2020 to November 2020. The technical team has developed the INCA App as shown in figure 01, through the following steps: 1) Assess INCA patients' cancer care requirements, 2) develop an app tailored for cancer care management, 3) validate the app's usability, and 4) App installation on INCA patients' smartphone.

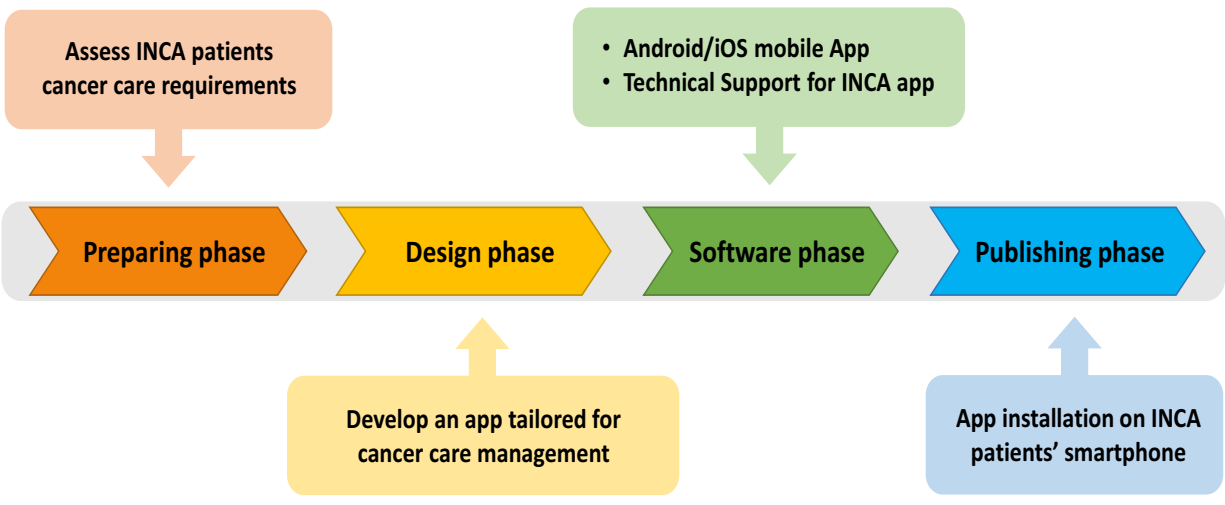

Figure 1. INCA App Implementation Phases.

For this implementation, a survey was carried out at INCA hospital units through more than 50 semi-structured interviews with patients and family members. The APP requirements implemented at the first stages of the project remarked that the application should be available on the most used platforms.

The cancer treatment management application was developed to enhance the patientclinician relationship and guarantees patients' data consistency and accuracy. The app can effectively track and manage INCA patients during cancer treatment in an interactive and engaging framework.

This technology can reduce administrative burdens and improve both efficiency and quality of care delivery in the clinic. Among the patients identified as mHealth users, approximately half of the respondents used INCA mobile technologies for automation and decision-making support to schedule an appointment, access personal information, and read test results. 


\section{Results}

INCA patients can instantly receive notifications of appointments/exam booking, medication prescription, and cancer prevention education messages through the application. Patients could access supportive cancer care with effective clinician interaction, regardless of place and time. Among the main functionalities created to facilitate the INCA patient's cancer care, as shown in figure 02, the following can be highlighted:
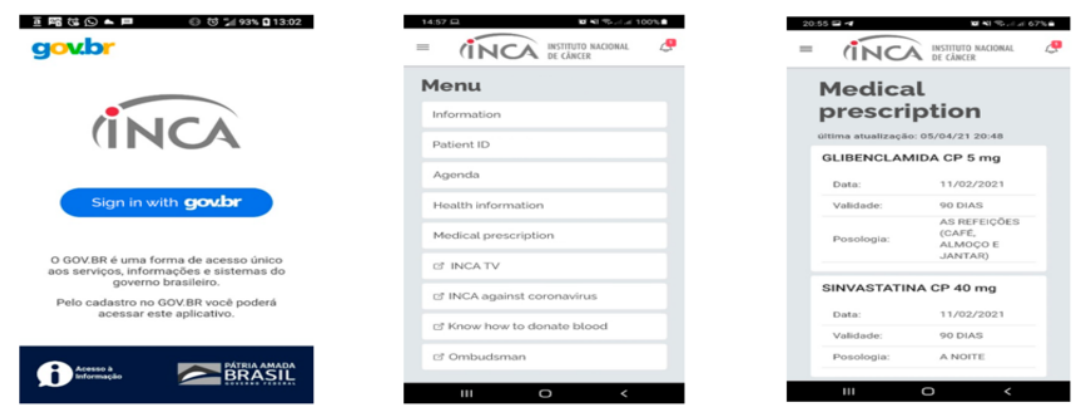

Figure 2. INCA App Screenshot.

- Digital patient's registration card. Its purpose is to facilitate the identification of the patient when he goes to INCA or any other health units;

- Appointments and exams scheduling to inform and alert the user on which dates, times, and units should attend for consultations and exams;

- Medical information briefly presents the type of neoplasia, diagnosis date, staging, and patient's situation. It is a facilitator so that the patient, whenever necessary, has the information readily available to present to health professionals who provide care in other health units;

- List of medications in use during his treatment at INCA. Likewise, it is a facilitator so that the patient, whenever necessary, has the information readily available to present to health professionals.

- Ombudsman Channel facilitates communication between patients and the Ombudsman sector to make complaints, suggestions, and requests.

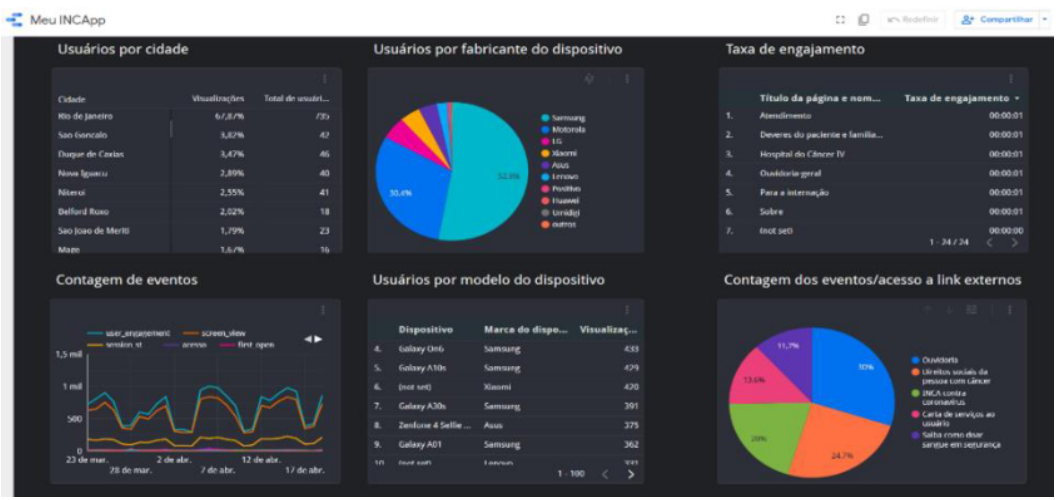

Figure 3. INCA App Panel Screenshot. 
The resources used to monitor the INCA App provide information and indicators for decision-making of future improvements, made available through a panel with graphics when the application is in use. The Panel was created on the development platform Firebase, Google, whose purpose is to collect information recorded on each cell phone of INCA patients to provide statistical data, as shown in figure 03 .

\section{Discussion}

Modern technologies like mobile apps are increasingly improving healthcare services with innovative solutions. Advances in wireless technology can lead to the development of mHealth, which offers an unprecedented opportunity for health care organizations to deliver high-quality care. These innovations empower cancer patients to be strategic actors in managing their treatment through mobile devices.

Implementing mobile applications in healthcare organizations can support cancer care management, increase satisfaction, and strengthen trust and communication between patients, physicians, and clinicians. Mobile app facilitates treatment follow-up and improves patients data consistency.

Advances in information technology and the development of mobile apps may enable the deployment of powerful tools to deliver personalized cancer care management. The INCA app tracks patients' treatment data, provides cancer-prevent education and identifies evidence-based recommendations for cancer treatment interventions personalized to the INCA environment.

\section{References}

[1] Steinhubl SR, Muse ED, Topol EJ. Can mobile health technologies transform health care? J Am Med Assoc Dec 2013;310(22):2395-2396.

[2] Tarricone R, Cucciniello M, Armeni P, Petracca F, Desouza K, Hall L, Keefe D. Mobile Health Divide Between Clinicians and Patients in Cancer Care: Results from a Cross-Sectional International Survey. JMIR mHealth uHealth. 2019;7(9).

[3] Noah B, Keller MS, Mosadeghi S, Stein L, John S, Delshad S. Impact of remote patient monitoring on clinical outcomes: an updated meta-analysis of randomized controlled trials. NPJ Digit Med. Jan 2018;1(1).

[4] Collado-Borrell R, Escudero-Vilaplana V, Calles A, Garcia-Martin E, Marzal-Alfaro B, Gonzalez-Haba E. Oncology patient interest in the use of new technologies to manage their disease: a cross-sectional survey. Jouneal Med Internet Res. 2018;20(10).

[5] Jongerius C, Russo S, Mazzocco, K. Research-tested mobile apps for breast cancer care systematic review. JMIR Mhealth Uhealth. 2019;7;e10930.

[6] El Shafie RA, Weber D, Bougatf N, Sprave T, Oetzel D, Huber PE, Debus J, Nicolay NH. Supportive care in radiotherapy based on a mobile app: a prospective multicenter survey. JMIR MHealth and UHealth. 2018;6:1-14.

[7] de Castro Silva SL, Gonçalves AA, Cheng C, Martins CH. Mobile Technology Applications in Cancer Palliative Care. InpHealth 2018 Jun 5 (pp. 199-202). 